\title{
Aging and mfERG topography
}

\begin{abstract}
Aim To study the effect of aging retina on the multifocal electroretinogram (mfERG). Methods A total of 18 young subjects (age 18-24 years) and 36 elderly subjects (aged 60-85 years) with intraocular lenses (IOLs) were recruited for this study. No subjects had significant eye diseases or media opacities. mfERG was measured in standard conditions using the VERIS system (version 4.1). There were three groups of 18 subjects: (1) 18-25 years, (2) 60-70 years, and (3) 75-85 years. mfERG responses were grouped into central, paracentral, and peripheral regions for analysis. The N1 amplitude, P1 amplitude, N1 latency, and P1 latency of the first-order responses were analysed.

Results Age had no effect on P1 latency, N1 amplitude, and P1 amplitude; however, N1 latencies from central to peripheral regions were significantly longer for group 3 than for group 1.

Conclusions This study suggests that measured age-related decreases in mfERG responses are due to optical factors (decrease in retinal light levels, scatter) before the age of 70 years, but neural factors significantly affect mfERG topography after the age of $\mathbf{7 0}$ years. Eye (2006) 20, 18-24. doi:10.1038/sj.eye.6701777; published online 24 December 2004
\end{abstract}

Keywords: light scattering; aging; mfERG; cataract

\section{Introduction}

Many aspects of human visual function change with age, including visual acuity, contrast sensitivity, colour vision, visual field, and dark adaptation. ${ }^{1-4}$ The decline of visual function with age could be due to optical factors or neural factors. Age-related optical changes include the light absorption and light scattering caused by the crystalline lens., 5 Age-related neural changes include the loss of rods, cones, and ganglion cells. ${ }^{7-9}$ Psychophysical studies
W-K Tam¹, H Chan', B Brown², K-W Leung1, $\checkmark$ Woo $^{3}$ and M Yap ${ }^{1}$

have demonstrated that rod-mediated sensitivity for older people is significantly lower than for younger people, ${ }^{10,11}$ and it has been found that foveal cone sensitivity also decreases with increasing age, especially after the age of 50 years. ${ }^{12,13}$ Earlier electrophysiological studies have shown age-related retinal changes using various ERG test protocols. ${ }^{14,15}$ Since the development of the multifocal electroretinogram (mfERG), ${ }^{16}$ age-related retinal changes can be studied topographically. The standard mfERG allows us to examine the contribution of receptors and bipolar cells to the electrical response of the eye. ${ }^{17}$

The effects of aging on mfERG topography have been studied extensively in recent years. ${ }^{18-23}$ Most of these studies have found that both central and peripheral mfERG responses decrease with increasing age, but the decrease is more prominent in the central retina. ${ }^{18-21,23}$ However, the age-related decrease of mfERG responses could be due to optical factors (e.g. lens opacities) and neural factors. Therefore, pseudophakes are an excellent model for study of neural deficits.

The aim of this study was to investigate the neural effects of aging on mfERG topography, by examining patients after IOL implant surgery; we compared mfERG topography in young subjects and two groups of older subjects with IOLs. Amplitudes and latencies of the first-order mfERG responses were analysed in this study.

\section{Method}

\section{Subjects}

We examined 54 subjects whose ages ranged from 18 to 85 years. Each of three groups contained 18 subjects of similar age: (1) 18-25, (2) 60-70, and (3) 75-85 years. All subjects in groups 2 and 3 had undergone cataract surgery (phacoemulsification) with IOLs implanted, without postoperative complications. The subjects in group 1 were students at The Hong Kong Polytechnic University and the subjects in groups 2 and 3 were recruited from a private eye clinic. 
All of the subjects were in good general health. To ensure that all subjects were free of retinal disease in the tested eye, they received an eye examination including visual acuity assessment, biomicroscopy, intraocular pressure measurement, and indirect ophthalmoloscopy. All subjects in this study had corrected visual acuity of $6 / 6$ or better and refractive errors less than $\pm 3.00 \mathrm{D}$ with less than $1.00 \mathrm{D}$ astigmatism.

Research procedures in this study followed the tenets of the Declaration of Helsinki. All procedures were approved by the ethics committee of The Hong Kong Polytechnic University. Informed consent was obtained from all participating subjects after they were given an explanation of the study.

\section{Stimulus conditions}

The VERIS Science 4.1. system (Electro Diagnostic Imaging Inc., San Mateo, CA, USA) was used to record mfERG. The stimulus matrix consisted of 103 scaled hexagonal elements presented on a high-resolution RGB $19^{\prime \prime}$ monitor (Sony, GDM-500P3, Japan) with frame rate of $75 \mathrm{~Hz}$, which was controlled by a video card (from EDI) in a Macintosh G3 computer. The stimulus hexagons were individually modulated between white $\left(165 \mathrm{~cd} / \mathrm{m}^{2}\right)$ and black $\left(3 \mathrm{~cd} / \mathrm{m}^{2}\right)$ according to a pseudorandom m-sequence. ${ }^{16}$ The luminance of the surround was set at $84 \mathrm{~cd} / \mathrm{m}^{2}$. The monitor subtended a viewing angle of $45^{\circ}$ vertically and $56.6^{\circ}$ horizontally. A red central cross $\left(0.8^{\circ}\right.$ : pen diameter $1 \%$ ) was used to assist fixation.

The diameter of different stimulus rings were: Ring 1: about $8.9^{\circ}$; Ring 2 : about $8.9^{\circ}-25.2^{\circ}$; Ring 3 : about $25.2^{\circ}-43.8^{\circ}$. These were modelled on those used by Seiple et al. ${ }^{18}$

\section{Recording conditions}

Pupils were dilated with $1 \%$ tropicamide (Mydriacyl, Alcon, Belgium) to pupil size of at least $6 \mathrm{~mm}$. In this study, the average dilated pupil size for elderly group was not statistically significantly different compared to the young groups. A Dawson-Trick-Litzkow (DTL) electrode was used as the active electrode. The reference and ground electrodes ( $\mathrm{Ag}-\mathrm{AgCl}$ electrode) were attached to the ipsilateral outer canthus and forehead, respectively. Only one eye of each subject was tested and the other eye was occluded during recording. Refractive errors were fully corrected for the $35 \mathrm{~cm}$ viewing distance. The signals were amplified by 100000 with band-pass from 3 to $300 \mathrm{~Hz}$ (Grass Instrument Co., Quincy, MA, USA). No line filter was used. A binary msequence of $2^{15}$ was used for recording mfERG. Total recording time was $7 \mathrm{~min} 17 \mathrm{~s}$ in each complete recording. Each recording was collected in 32 segments, each approximately $14 \mathrm{~s}$ in length; subjects rested for a few seconds between segments. Any segment with breaks of fixation, eye movements, or blinks was discarded and recorded again. The recording conditions were performed according to the ISCEV guidelines.

\section{Analysis}

For the purpose of data analysis, mfERG responses were grouped into three regions: (a) central, (b) paracentral, and (c) peripheral (Figure 1). ${ }^{18}$

In this study, the first-order kernel responses were analysed. Amplitudes and latencies of N1 and P1 were evaluated. The effects of aging on central, paracentral, and peripheral regions were evaluated by two-way ANOVA (using three groups $\times$ three regions as the main factors). The Tukey HSD multiple comparisons test was used as post hoc test. $P$-values less than 0.05 were considered statistically significant.

\section{Results}

There are no effects of age on N1 amplitude, but there are statistically significant effects of region grouping on this parameter for each age group (Table 1; Figure 2a). Tukey HSD multiple comparisons test shows that N1 amplitude among these three regions differs significantly. There is no significant interaction of age and region grouping for N1 amplitude. Findings are similar for P1 amplitude (Table 1; Figure 2b); P1 amplitude decreases significantly with increasing eccentricity as expected, but there are no statistically significant effects of age and no significant interaction effects.

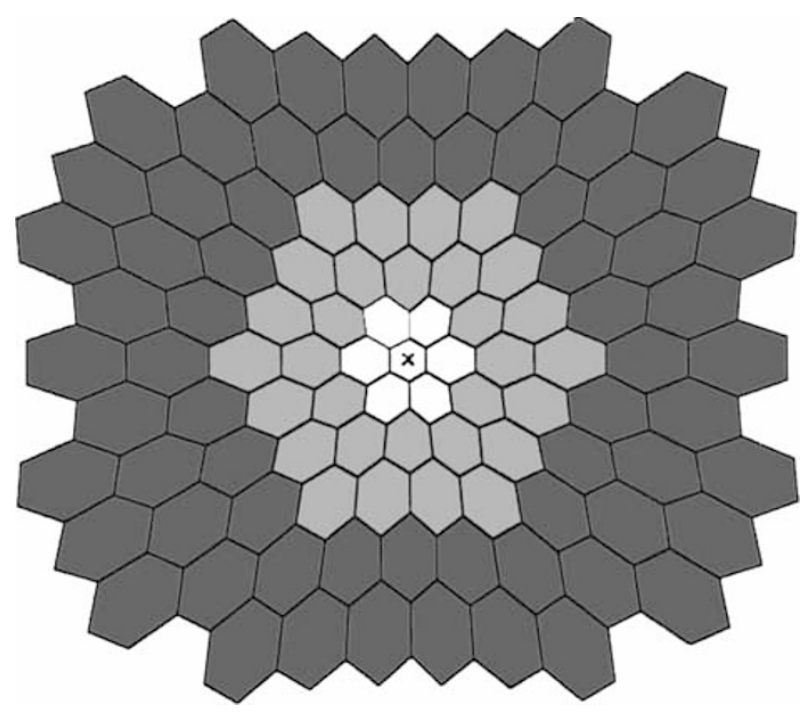

Figure 1103 local responses were grouped into three regions for analysis: central, paracentral, and peripheral. 
Table 1 Effect of aging on mfERG responses parameters and statistical findings: responses from three regions

\begin{tabular}{|c|c|c|c|c|}
\hline & Group 1 & Group 2 & Group 3 & Two-way ANOVA \\
\hline \multicolumn{5}{|c|}{ N1 amplitude (nV/deg $\left.{ }^{2}\right)$} \\
\hline Region 1 & $15.77 \pm 1.00$ & $14.18 \pm 0.82$ & $13.57 \pm 1.35$ & Group, $P=0.257, \mathrm{~F}[2,153]=1.372$ \\
\hline Region 2 & $6.49 \pm 0.48$ & $6.45 \pm 0.54$ & $5.69 \pm 0.52$ & Region, $P=0.000^{*}, \mathrm{~F}[2,153]=176.6$ \\
\hline Region 3 & $3.74 \pm 0.32$ & $4.78 \pm 0.33$ & $3.99 \pm 0.28$ & Interaction, $P=0.379, \mathrm{~F}[4,153]=1.059$ \\
\hline \multicolumn{5}{|c|}{ P1 amplitude (nV/deg $\left.{ }^{2}\right)$} \\
\hline Region 1 & $32.98 \pm 1.61$ & $31.04 \pm 1.54$ & $31.25 \pm 1.93$ & Group, $P=0.551, F[2,153]=0.599$ \\
\hline Region 2 & $13.84 \pm 0.66$ & $15.72 \pm 0.98$ & $14.38 \pm 1.03$ & Region, $P=0.000^{*}, \mathrm{~F}[2,153]=290.4$ \\
\hline Region 3 & $8.03 \pm 0.51$ & $10.68 \pm 0.88$ & $8.88 \pm 0.85$ & Interaction, $P=0.376, F[4,153]=1.065$ \\
\hline \multicolumn{5}{|c|}{ N1 latency (ms) } \\
\hline Region 1 & $18.99 \pm 0.35$ & $19.09 \pm 0.73$ & $19.60 \pm 0.55$ & Group, $P=0.013^{*}, \mathrm{~F}[2,153]=4.469$ \\
\hline Region 2 & $17.74 \pm 0.22$ & $19.15 \pm 0.57$ & $19.32 \pm 0.59$ & Region, $P=0.164, F[2,153]=1.831$ \\
\hline Region 3 & $18.80 \pm 0.36$ & $19.47 \pm 0.45$ & $20.26 \pm 0.49$ & Interaction, $P=0.714, F[4,153]=0.530$ \\
\hline \multicolumn{5}{|c|}{ P1 latency (ms) } \\
\hline Region 1 & $33.63 \pm 0.62$ & $34.54 \pm 0.73$ & $34.69 \pm 0.70$ & Group, $P=0.183, \mathrm{~F}[2,153]=1.717$ \\
\hline Region 2 & $34.41 \pm 0.64$ & $34.88 \pm 0.73$ & $35.43 \pm 0.70$ & Region, $P=0.376, \mathrm{~F}[2,153]=0.983$ \\
\hline Region 3 & $34.58 \pm 0.61$ & $34.87 \pm 0.78$ & $35.63 \pm 0.71$ & Interaction, $P=0.991, F[4,153]=0.069$ \\
\hline
\end{tabular}

Data are presented as mean \pm SEM.

*Significant difference $(P<0.05)$.

There is a statistically significant latency effect for the N1 component (Table 1; Figure 2c). The mean N1 latency of the younger subject group (Group 1) is faster than those of Group 2 by about $0.72 \mathrm{~ms}$, and the mean N1 latency of Group 2 is faster than those of Group 3 by about $0.49 \mathrm{~ms}$, but these changes are not statistically significant. However, Tukey HSD multiple comparisons test only shows that N1 latency from group 1 significantly differs from group $3(P=0.01)$. There is no statistically significant retinal location effect and no significant interaction effect. For P1 latency however, while the trends in timing of the responses are similar to those of the N1 response (Table 1; Figure 2d), there are no statistically significant effects for age group, regions, and no interaction effect. The typical waveforms of $\mathrm{mfERG}$ in these three groups of subjects are shown in Figure 3.

\section{Discussion}

The number of cells in the human cerebral cortex decreases with increasing age $\mathrm{e}^{24}$ and the function and anatomical structure of the retina also change during aging. $7,9,25,26$ It is well known that visual functions such as visual acuity, contrast sensitivity, vernier acuity, and colour vision decrease with increasing age. ${ }^{1,27}$

Nevertheless, some of the visual functions are reported to be resistant to age-related changes. ${ }^{28}$ These findings imply that not all kinds of neurons in the visual system are affected by age. ${ }^{28}$
By removing the optical factors, our study shows that neural factors are not responsible for the previously reported age-related decrease of $\mathrm{mfERG}$ responses amplitude in the central retina. We found only a main effect of age on mfERG N1 latency; our results showed that N1 latency increased significantly when we compared young subjects and pseudophakic subjects over 75 years of age. Our results indicate that age-related changes of mfERG topography before the age of 70 years are caused by optical factors rather than neural factors.

An early study comparing mfERG topography in different age groups (18-22, 33-37, and 48-52 years) showed that P1 amplitude from the central retina $\left(10^{\circ}\right.$ in diameter) decreased significantly in the oldest group, ${ }^{22}$ but this study did not show changes in N1 amplitude, N1 latency, or P1 latency with increasing age. However, Tzekov et $a l^{29}$ showed that P1 amplitude and P1 latency decreased with increasing age. They also found that the decrease of P1 amplitude from superior retina was faster than inferior retina, but the decrease was similar for the nasal and temporal retina. Nabeshima et $a l^{30}$ also found that subjects over 40 years of age showed reduced P1 amplitudes from central retinal regions $\left(6.4^{\circ}\right.$ in diameter). Subjects over 50 years of age had lower P1 amplitudes in the central and peripheral retina $\left(50^{\circ}\right.$ diameter $)$ compared to 20-year-old subjects. However, P1 latencies did not change significantly with increasing age regardless of eccentricity.

Jackson et $a l^{21}$ examined the effect of pupil size and media opacities on mfERG topography. They 
a

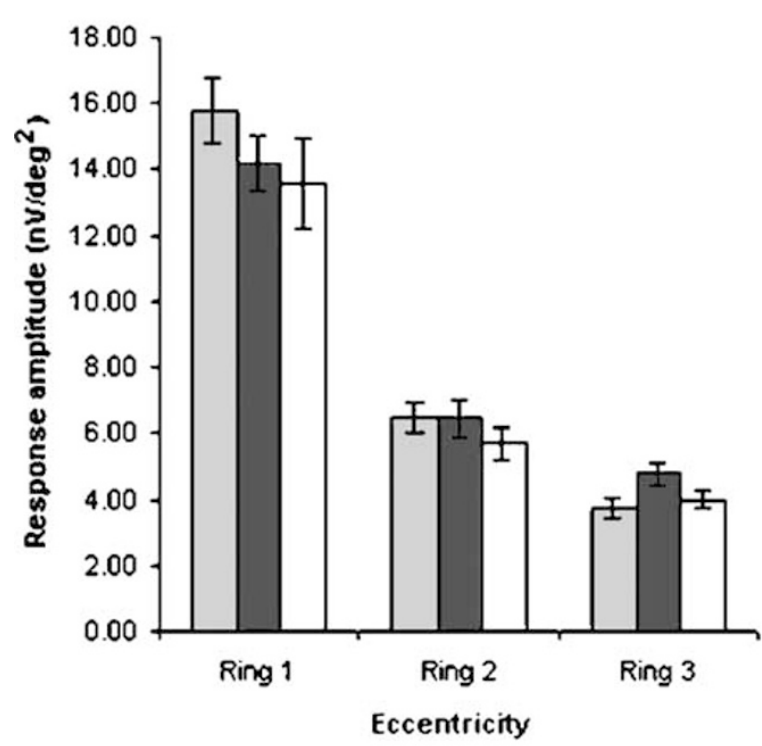

C

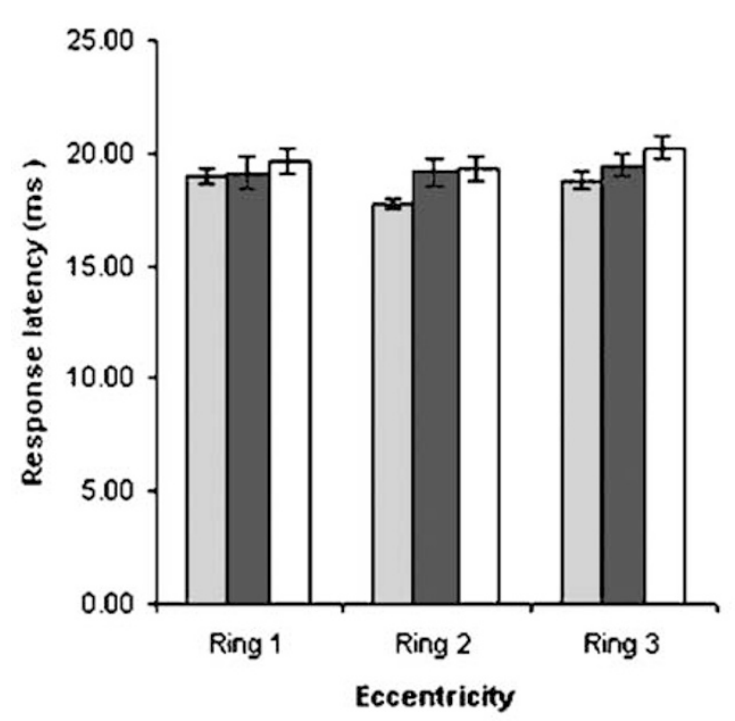

b

Effect of aging on $\mathrm{P}_{1}$ amplitude

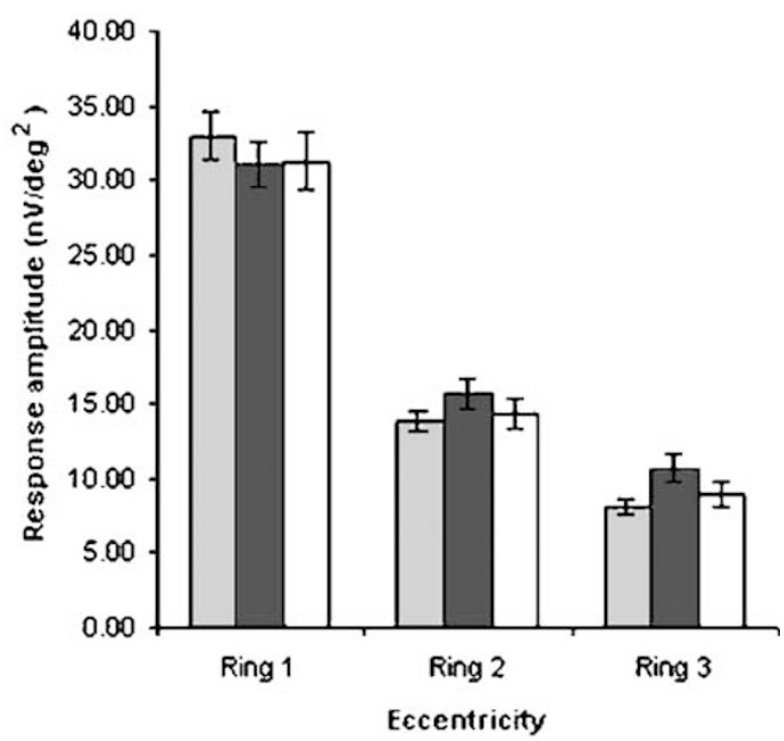

d

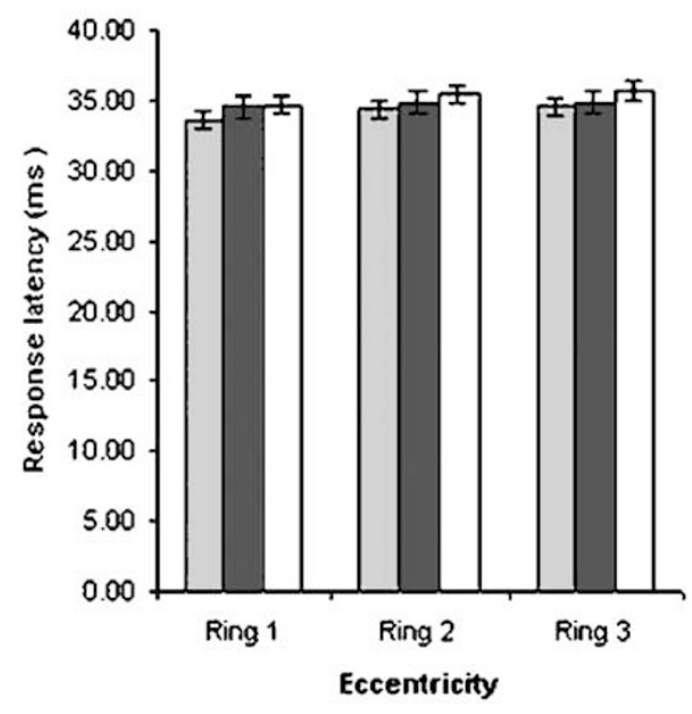

๑Group $1 \quad \square$ Group $2 \quad$ oGroup 3

Figure 2 (a) Mean N1 amplitude, (b) mean P1 amplitude, (c) mean N1 latency, and (d) MEAN P1 latency of three regions for three groups of subjects of different ages. Error bars are \pm 1 SEM.

demonstrated that pupil size and media opacities could reduce mfERG responses. They concluded that both optical factors and neural factors (eg slowed temporal adaptation in the aged retina) caused the age-related changes in mfERG topography. Without accounting for the effects of pupil size and media opacities, Jackson et $a l^{21}$ also found that both central and peripheral retinal responses (N1 and P1) decreased with increasing age and the greatest reduction occurred in the central $10^{\circ}$ of the retina. They further showed that average N1 and P1 latencies in older subjects were longer than in young subjects. However, Dolan et $a l^{31}$ showed that P1 amplitude and latency in the peripheral retina (60-90 of visual field) did not change significantly with increasing age even in subjects up to 75 years of age.

Our results were similar to those of Fortune and Johnson ${ }^{19}$ who showed that P1 amplitude decreased and P1 latency increased at all eccentricities with increasing age in normal; they attributed the decline of mfERG responses with age to optical factors rather than to neural 

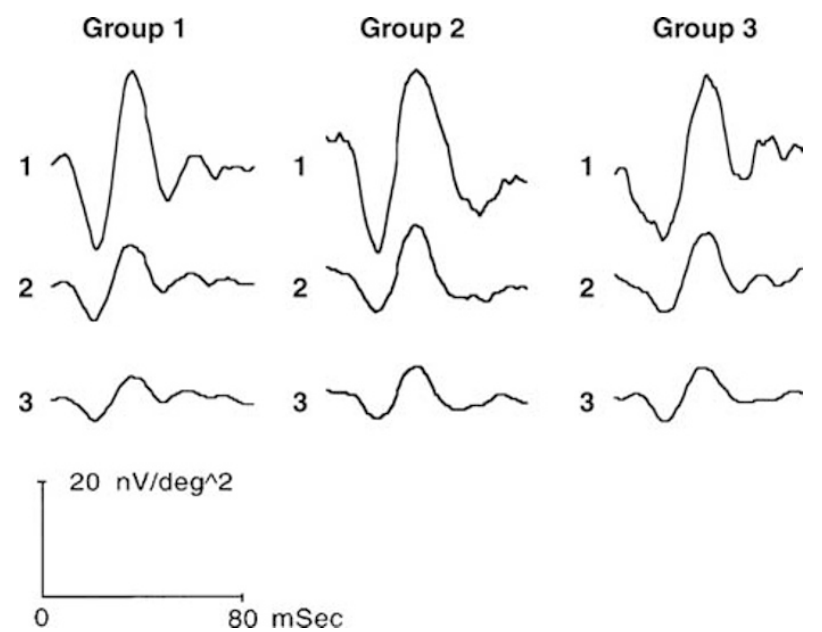

Figure 3 mfERG from three of subjects for the three concentric rings.

factors. ${ }^{19}$ After adjusting for the effects of preretinal optical factors, they showed that P1 latency did not change significantly with age and only P1 amplitude from the central retina was slightly reduced with age. However, Gerth et al ${ }^{32}$ showed that optical factors, which reduce retinal illuminance and increase intraocular scattering, could not fully account for the age-related decrease in mfERG response. They believed that the reduced responses in aged subjects might be attributable to age-related cell loss in the retina. ${ }^{20}$ Their later study further demonstrated that the aging effect could also be observed in 'isolated flash responses' as well as 'adapted responses', ${ }^{32}$ implying a neural basis for the effect.

Recently, Seiple et al $^{18}$ have claimed that mfERG

amplitude reduction with increasing age is mainly due to neural factors. They showed that central retinal responses decrease at a greater rate than the peripheral retinal responses. In addition, N1 latency and P1 latency tended to increase 0.02 and $0.03 \mathrm{~ms}$ per year, respectively; they examined subjects up to 81 years of age. All their subjects had best corrected VA of 20/25 and passed the Pelli-Robson contrast sensitivity test. The Pelli-Robson chart measures contrast sensitivity $(0.5-2 \mathrm{c} / \mathrm{deg})$ just below the peak of the contrast sensitivity function (2-6c/ deg). As media opacities (eg cataract) have a greater effect on high spatial frequencies $(5-10 \mathrm{c} / \mathrm{deg})$ than low spatial frequencies $(1 \mathrm{c} / \mathrm{deg}){ }^{33}$ the Pelli-Robson chart does not provide a more sensitive measure of cataract than VA. ${ }^{34,35}$ Therefore, the confounding effects of preretinal optical factors on mfERG responses might still be present in their subjects. As recent studies have found that cataract could reduce $\mathrm{mfREG}$ responses, the preretinal optical factors should be noticed. ${ }^{36-38}$

We believe that previous studies, which showed a significant decrease in mfERG response amplitude and an increase in mfERG response latency, may be due to the confounding effect of media opacities and the instability of fixation. ${ }^{19,39,40}$ The different results reported by different studies may be due to different methodologies (eg stimulus luminance and band-pass ${ }^{41,42}$ ), assumptions, ${ }^{19,21}$ and different criteria for subject inclusion.

Since the ERG is an objective method of assessing retinal function, the effects of age on mfERG topography could be theoretically predicted by knowing the anatomical changes of the aged retina and the origin of mfERG. An earlier well-known study by Gao and Hollyfield ${ }^{9}$ found that foveal cone density did not decrease significantly with increasing age even in subjects up to the age of 95 years, but cone density at the equator decreases linearly with increasing age. Only 6.7 and $23 \%$ of cones at the retinal equator were lost at the fourth decade and ninth decade, respectively. ${ }^{9}$ Their results were well supported by Curcio et $a l^{6}$ who showed that cone density in the rod-free fovea and the extrafoveal region did not change significantly with increasing age even in a retina aged 90 years. In contrast to the loss of cones, rods appear to be more vulnerable to loss by aging. Both Gao and Hollyfield ${ }^{7}$ and Curcio et al ${ }^{6}$ have found about $30 \%$ loss of rods in the ninth decade.

Unfortunately, the effects of aging on the anatomy of bipolar cells in primates have not yet been reported. ${ }^{43}$ It has been reported that there are no age-related changes in amacrine cells within the central $5 \mathrm{~mm}$ of the retina. ${ }^{8}$ Anatomical studies have shown a progressive decrease in the number of ganglion cells with increasing age, with a more prominent decrease in the peripheral retina. ${ }^{9,44}$

The main contributions to the human mfERG are from cells of the outer retina. The leading edge of N1 is most probably related to the onset of the off-bioplar cells with a small contribution from the cones. The leading edge of P1 is related to on-bipolar cells and off-bipolar cells. ${ }^{45}$ Under photopic conditions, it is believed that the rod system does not provide any contribution to mfERG responses, as it is suppressed by the high frequency and high luminance stimulus. ${ }^{41,45}$ In addition, damage to retinal ganglion cells or amacrine cells does not affect mfERG amplitude significantly ${ }^{46,47}$ and such damage has only slight effects on mfERG waveform. ${ }^{45}$ The contribution of ganglion cells to the mfERG response would only be revealed under a specific condition and a specific set-up. ${ }^{48}$ Since mfERG may be predominantly generated by bipolar cells and such a contribution is driven by functional photoreceptors, only damage of the cones cell or bipolar cells greatly decreases mfERG amplitude. $^{17}$

Our results have shown that central, paracentral, or peripheral mfERG responses to $44^{\circ}$ of the central retina do not change significantly with increasing age; this 
implies that the functional abilities of cone and bipolar cells do not decline significantly before 70 years of age. In addition, only the N1 latency of mfERG responses in our oldest group was significantly longer than that of our youngest group. This implies that age-related retinal changes occur late in life (ie after 70 years of age). The results of this study suggest that when we measure mfERG in patients with IOLs, we should expect amplitude and latency values similar to those of young subjects. Increased latency and decreased amplitude in patients with IOLs is likely to imply abnormal retinal function.

\section{Acknowledgements}

This study was supported by the Competitive Earmark Research Grant (PolyU 5277/01 M) from The Research Grants Committee in Hong Kong SAR.

\section{References}

1 Hurst MA, Douthwaite WA. Assessing vision behind cataract-a review of methods. Optom Vis Sci 1993; 70: 903-913.

2 Werner JS, Peterzell DH, Scheetz AJ. Light, vision, and aging. Optom Vis Sci 1990; 67: 214-229.

3 Jackson GR, Owsley C, McGwin Jr G. Aging and dark adaptation. Vision Res 1999; 39: 3975-3982.

4 Johnson CA, Adams AJ, Lewis RA. Evidence for a neural basis of age-related visual field loss in normal observers. Invest Ophthalmol Vis Sci 1989; 30: 2056-2064.

5 Hennelly ML, Barbur JL, Edgar DF, Woodward EG. The effect of age on the light scattering characteristics of the eye. Ophthalmic Physiol Opt 1998; 18: 197-203.

6 Sample PA, Esterson FD, Weinreb RN, Boynton RM. The aging lens: in vivo assessment of light absorption in 84 human eyes. Invest Ophthalmol Vis Sci 1988; 29: 1306-1311.

7 Curcio CA, Millican CL, Allen KA, Kalina RE. Aging of the human photoreceptor mosaic: evidence for selective vulnerability of rods in central retina. Invest Ophthalmol Vis Sci 1993; 34: 3278-3296.

8 Curcio CA, Drucker DN. Retinal ganglion cells in Alzheimer's disease and aging. Ann Neurol 1993; 33: 248-257.

9 Gao H, Hollyfield JG. Aging of the human retina. Differential loss of neurons and retinal pigment epithelial cells. Invest Ophthalmol Vis Sci 1992; 33: 1-17.

10 Sturr JF, Zhang L, Taub HA, Hannon DJ, Jackowski MM. Psychophysical evidence for losses in rod sensitivity in the aging visual system. Vision Res 1997; 37: 475-481.

11 Jackson GR, Owsley C, Cordle EP, Finley CD. Aging and scotopic sensitivity. Vision Res 1998; 38: 3655-3662.

12 van Norren D, van Meel GJ. Density of human cone photopigments as a function of age. Invest Ophthalmol Vis Sci 1985; 26: 1014-1016.

13 Kilbride PE, Hutman LP, Fishman M, Read JS. Foveal cone pigment density difference in the aging human eye. Vision Res 1986; 26: 321-325.
14 Weleber RG. The effect of age on human cone and rod ganzfeld electroretinograms. Invest Ophthalmol Vis Sci 1981; 20: 392-399.

15 Birch DG, Anderson JL. Standardized full-field electroretinography. Normal values and their variation with age. Arch Ophthalmol 1992; 110: 1571-1576.

16 Sutter EE, Tran D. The field topography of ERG components in man-I. The photopic luminance response. Vision Res 1992; 32: 433-446.

17 Hood DC, Odel JG, Chen CS, Winn BJ. The multifocal electroretinogram. J Neuroophthalmol 2003; 23: 225-235.

18 Seiple W, Vajaranant TS, Szlyk JP, Clemens C, Holopigian K, Paliga $\mathrm{J}$ et al. Multifocal electroretinography as a function of age: the importance of normative values for older adults. Invest Ophthalmol Vis Sci 2003; 44: 1783-1792.

19 Fortune B, Johnson CA. Decline of photopic multifocal electroretinogram responses with age is due primarily to preretinal optical factors. J Opt Soc Am A Opt Image Sci Vis 2002; 19: 173-184.

20 Gerth C, Garcia SM, Ma L, Keltner JL, Werner JS. Multifocal electroretinogram: age-related changes for different luminance levels. Graefes Arch Clin Exp Ophthalmol 2002; 240: 202-208.

21 Jackson GR, Ortega J, Girkin C, Rosenstiel CE, Owsley C. Aging-related changes in the multifocal electroretinogram. J Opt Soc Am A Opt Image Sci Vis 2002; 19: 185-189.

22 Mohidin N, Yap MK, Jacobs RJ. Influence of age on the multifocal electroretinography. Ophthalmic Physiol Opt 1999; 19: 481-488.

23 Nabeshima T, Tazawa Y, Mita M, Sano M. Effects of aging on the first and second-order kernels of multifocal electroretinogram. Jpn J Ophthalmol 2002; 46: 261-269.

24 Henderson G, Tomlinson BE, Gibson PH. Cell counts in human cerebral cortex in normal adults throughout life using an image analysing computer. J Neurol Sci 1980; 46: 113-136.

25 Liem AT, Keunen JE, van Norren D, van de Kraats J. Rod densitometry in the aging human eye. Invest Ophthalmol Vis Sci 1991; 32: 2676-2682.

26 Jackson GR, Owsley C, Curcio CA. Photoreceptor degeneration and dysfunction in aging and age-related maculopathy. Ageing Res Rev 2002; 1: 381-396.

27 Li RW, Edwards MH, Brown B. Variation in vernier acuity with age. Vision Res 2000; 40: 3775-3781.

28 Enoch JM, Werner JS, Haegerstrom-Portnoy G, Lakshminarayanan V, Rynders M. Forever young: visual functions not affected or minimally affected by aging: a review. J Gerontol A Biol Sci Med Sci 1999; 54: B336-B351.

29 Tzekov RT, Gerth C, Werner JS. Senescence of human multifocal electroretinogram components: a localized approach. Graefes Arch Clin Exp Ophthalmol 2004; 242: 549-560.

30 Nabeshima T. The effects of aging on the multifocal electroretinogram. Jpn J Ophthalmol 2001; 45: 114-115.

31 Dolan FM, Parks S, Keating D, Dutton GN, Evans AL. Multifocal electroretinographic features of central retinal vein occlusion. Invest Ophthalmol Vis Sci 2003; 44: 4954-4959.

32 Gerth C, Sutter EE, Werner JS. mfERG response dynamics of the aging retina. Invest Ophthalmol Vis Sci 2003; 44: $4443-4450$

33 Elliott DB, Gilchrist J, Whitaker D. Contrast sensitivity and glare sensitivity changes with three types of cataract morphology: are these techniques necessary in a clinical evaluation of cataract? Ophthalmic Physiol Opt 1989; 9: 25-30. 
34 Elliott DB. Evaluating visual function in cataract. Optom Vis Sci 1993; 70: 896-902.

35 Lempert P, Hopcroft M, Lempert Y. Evaluation of posterior subcapsular cataracts. With spatial contrast acuity. Ophthalmology 1987; Pt 2: 14-18.

36 Wordehoff UV, Palmowski AM, Heinemann-Vernaleken B, Allgayer R, Ruprecht KW. Influence of cataract on the multifocal ERG recording - a pre- and postoperative comparison. Doc Ophthalmol 2004; 108: 67-75.

37 Tam A, Chan H, Brown B, Yap M. The effects of forward light scattering on the multifocal electroretinogram. Curr Eye Res 2004; 28: 63-72.

38 Tam WK, Chan H, Brown B, Yap M. Effects of different degrees of cataract on the multifocal electroretinogram. Eye 2004; 18: 691-696.

39 Rudolph G, Kalpadakis P. The role of fixation for reliable mfERG results. Graefes Arch Clin Exp Ophthalmol 2002; 240: 874-875; author reply 876-877.

40 Vrabec TR, Affel EL, Gaughan JP, Foroozan R, Tennant MT, Klancnik Jr JM et al. Voluntary suppression of the multifocal electroretinogram. Ophthalmology 2004; 111: 169-176.

41 Keating D, Parks S, Evans A. Technical aspects of multifocal ERG recording. Doc Ophthalmol 2000; 100: 77-98.
42 Han Y, Bearse Jr MA, Schneck ME, Barez S, Jacobsen C, Adams AJ. Towards optimal filtering of 'standard' multifocal electroretinogram (mfERG) recordings: findings in normal and diabetic subjects. Br J Ophthalmol 2004; 88: 543-550.

43 Spear PD. Neural bases of visual deficits during aging. Vision Res 1993; 33: 2589-2609.

44 Bonnel S, Mohand-Said S, Sahel JA. The aging of the retina. Exp Gerontol 2003; 38: 825-831.

45 Hood DC, Frishman LJ, Saszik S, Viswanathan S. Retinal origins of the primate multifocal ERG: implications for the human response. Invest Ophthalmol Vis Sci 2002; 43 1673-1685.

46 Hood DC, Greenstein VC, Holopigian K, Bauer R, Firoz B, Liebmann JM et al. An attempt to detect glaucomatous damage to the inner retina with the multifocal ERG. Invest Ophthalmol Vis Sci 2000; 41: 1570-1579.

47 Fortune B, Johnson CA, Cioffi GA. The topographic relationship between multifocal electroretinographic and behavioral perimetric measures of function in glaucoma. Optom Vis Sci 2001; 78: 206-214.

48 Sutter EE, Bearse Jr MA. The optic nerve head component of the human ERG. Vision Res 1999; 39: 419-436. 